\title{
Biotransformation and Biodegradation of Selected Nitroaromatics under Anaerobic Conditions
}

\author{
Elías Razo-F lores, ${ }^{*,+}$ Gatze Lettinga, and J im A. Field
}

Subdirección de Protección Ambiental, I nstituto Mexicano del Petróleo, Eje Central Lázaro Cárdenas 152, 07730 México D.F., México, and Department of Agricultural, Environmental and Systems Technology, Subdepartment of Environmental Technology, Wageningen Agricultural University, Bomenweg 2, 6700 EV Wageningen, The Netherlands

\begin{abstract}
The fate of four nitroaromatic compounds (5-nitrosalicylate, 5NSA; 4-nitrobenzoate, $4 \mathrm{NBC}$; 2,4-dinitrotoluene, 2,4DNT; nitrobenzene, NB) was studied in $160 \mathrm{~mL}$ laboratory-scale upward-flow anaerobic sludge bed reactors supplied with a mixture of volatile fatty acids and/or glucose as el ectron donors. All the nitroaromatics were transformed stoichiometrically to their corresponding aromatic amines. After prolonged reactor operation, 5NSA and $4 \mathrm{NBC}$ were completely mineralized to $\mathrm{CH}_{4}$ and $\mathrm{CO}_{2}$, whereas 2,4DNT was partially transformed to a nonidentified and nondegradable metabolite. Batch nitro-reduction experiments indicated that the position of the nitro group in relation to the other substituents in the aromatic ring plays a key role in the rate of the nitro-group reduction. The results obtained indicate that certain nitroaromatic compounds can be completely mineralized and serve as a carbon and energy source for anaerobic bacteria.
\end{abstract}

\section{Introduction}

Nitroaromatics such as nitrobenzene, nitrotoluenes, and nitrobenzoates are of considerable industrial importance. They enter the environment mainly through anthropogenic activities originating from the manufacture of dyes, explosives, and pesticides (F ishbein, 1984; Hartter, 1985). Several of these compounds are produced in amounts on the order of several thousands of tons annually, and it has been estimated that the production of nitroaromatics is on the order of $808 \mathrm{Mtons} / \mathrm{year}$ (Swoboda-Colberg, 1995). 2,4-Dinitrotoluene (2,4DNT), the major impurity resulting from the manufacture of TNT, is a starting material for the synthesis of toluenediisocyanate, used in the production of polyurethane foam (U.S. EPA, 1986) of which its U.S. production in 1995 summed up to 429000 tons (Spain, 1997).

Nitroaromatics, in general, have been shown to be toxic or mutagenic to many life forms (Fishbein, 1984; Hirzel, 1993; Kriek, 1979), being easily reduced by enzymes to nitroso and hydroxylamine derivatives (Andreoni et al., 1995). These derivatives may lead to the formation of either metahemoglobin, which is unable to bind oxygen, or of nitrosoamines, which are carcinogenic (Kriek, 1979). Most nitroaromatics are highly toxic to bacteria (Blum and Speece, 1991; Donlon et al., 1995) and, consequently, may inhibit microbial growth. In fact, the toxicity and the poor biodegradability exhibited by these compounds are the main bottlenecks in the application of microbial wastewater treatment processes.

In general, molecules substituted with el ectron-withdrawing groups such as nitro, azo, and chloro groups are quite resistant to electrophilic attack by oxygenases

* Corresponding author (telephone: 52533360 00, ext. 21135;

fax: 52558700 09; e-mail: erazo@www.imp.mx).

† Instituto Mexicano del Petróleo.

‡ Wageningen Agricultural University.
(Knackmuss, 1996; Rieger and Knackmuss, 1995). Consequently, they generally persist during aerobic wastewater treatment (Hallas and Alexander, 1983; McCormick et al., 1976). On the other hand, a nucleophilic mechanism of attack is common in anaerobic environments being favorable for the initial reductive attack of these compounds (Knackmuss, 1996; Rieger and Knackmuss, 1995). However, electron-donating functional groups, like aromatic amines, are troublesome for the nucleophilic attack of anaerobes (Knackmuss, 1992; Knackmuss, 1996; Schink, 1988). The presence of amino electron donating groups is expected to facilitate the electrophilic attack of aromatics. Most of the typical aromatic amine-end products from the anaerobic metabol ism of nitroaromatic pollutants are eliminated in aerobic biodegradability tests (Dickel et al., 1993; Field et al., 1995).

Nevertheless, there are several reports indicating the complete mineralization of some nitroaromatics under anaerobic conditions, which usually proceeds through reduction of the nitro group to the corresponding aromatic amine (Boyd et al., 1983; Donlon et al., 1996; Uberoi and Bhattacharya, 1997). In a previous report (Donlon et al., 1996), we have shown that 2-nitrophenol (2NP) was completely mineral ized in an upflow anaerobic sludge blanket (UASB) reactor even at concentrations 25 times higher than those that caused severe inhibition. In the present study, we evaluate the fate of selected nitroaromatics, namely, 5-nitrosalicylate (5NSA), 4-nitrobenzoate (4NBC), 2,4-dinitrotoluene (2,4DNT), and nitrobenzene (NB), in continuous UASB reactors.

\section{Materials and Methods}

Methanogenic Granular Sludge. Two kinds of methanogenic granular sludge were used as inoculum during the experiments: granular sludge from a full-scale UASB reactor treating chemical industry wastewater of 
Shell Nederland Chemie (Moerdijk, The Netherlands) and 2NP-adapted granular sludge which originated from a lab reactor (Donlon et al., 1996). The sludge was elutriated to remove fines and stored at $4{ }^{\circ} \mathrm{C}$ before use.

Basal Medium. The basal medium used in all experiments was as described elsewhere (Donlon et al., 1996) and contained the following $(\mathrm{mg} / \mathrm{L}$ unless otherwise stated): $\mathrm{NaHCO}_{3}(5000), \mathrm{NH}_{4} \mathrm{Cl}(280), \mathrm{CaCl}_{2} \cdot 2 \mathrm{H}_{2} \mathrm{O}$ (10), $\mathrm{K}_{2} \mathrm{HPO}_{4}(250), \mathrm{MgSO}_{4} \cdot 7 \mathrm{H}_{2} \mathrm{O}$ (100), yeast extract (100), $\mathrm{H}_{3} \mathrm{BO}_{3}(0.05), \mathrm{FeCl}_{2} \cdot 4 \mathrm{H}_{2} \mathrm{O}$ (2), $\mathrm{ZnCl}_{2}(0.05), \mathrm{MnCl}_{2} \cdot 4 \mathrm{H}_{2} \mathrm{O}$ (0.05), $\mathrm{CuCl}_{2} \cdot 2 \mathrm{H}_{2} \mathrm{O}(0.03),\left(\mathrm{NH}_{4}\right) \mathrm{SeO}_{3} \cdot 5 \mathrm{H}_{2} \mathrm{O}(0.05), \mathrm{AlCl}_{3} \cdot$ $6 \mathrm{H}_{2} \mathrm{O}(2), \mathrm{NiCl}_{2} \cdot 6 \mathrm{H}_{2} \mathrm{O}(0.05)$, EDTA (1), resazurin (0.2), and $36 \% \mathrm{HCl}(0.001 \mathrm{~mL} / \mathrm{L})$. The micronutrients were supplemented to the media for the continuous column experiments at a 10-fold lower concentration.

Analytical Methods. The nitroaromatic concentration in solution was determined five times per week by monitoring nitro group and aromatic ring absorbance at the ultraviol et (UV) and/or visible-light (vis) absorbance maxima. The UV-vis spectra of the compounds were recorded in $0.2 \mathrm{M}$ phosphate buffer $(\mathrm{pH} 7.0)$ absorbance on a Spectronic 60 spectrophotometer (Milton Roy/ Analytical Products Division, Ostende, Belgium) and a model 100-QS (Hellma Benelux, The Hague, The Netherlands) $1 \mathrm{~cm}$ quartz cuvette. Nitro-group reductions of $5 \mathrm{NSA}, 4 \mathrm{NBC}, 2,4 \mathrm{DNT}$, and NB were monitored at 280, 320,260 , and $310 \mathrm{~nm}$, respectively, and there were not interferences with the aromatic amines absorption at these wavel engths. Aromatic ring absorptions of 5NSA and 5-aminosalicylate (5ASA), 4NBC and 4-aminobenzoate ( $4 A B C)$, 2,4DNT and 2,4-diaminotoluene (2,4DAT), and NB and aniline (AN) were monitored at 231, 285, 229 , and $260 \mathrm{~nm}$, respectively. At these wavelengths the absorbance of the nitroaromatic and the corresponding aromatic amine were approximately the same. The molar extinction coefficients (units of $\mathrm{M}^{-1} \mathrm{~cm}^{-1}$ determined in $0.2 \mathrm{M}$ phosphate buffer, $\mathrm{pH} 7.0,20^{\circ} \mathrm{C}$ ) for the nitro group absorbance of 5NSA, 4NBc, and 2,4DNT are 4412, 1739, and 10755 , respectively. All absorbance data are reported as the absorption of the medium containing aromatic compounds corrected for the absorption of the control media (which contained no test compounds).

Authentic standards of nitroaromatics and their anaerobic reduced metabolites were al so analyzed periodically by reversed-phase high-pressure liquid chromatography (HPLC, Spectra-Physics model SP8810, Thermo Separation Products, Breda, The Netherlands). 5NSA, 4NBC, and $4 A B C$ were detected with the following method: a C18 reverse-phase column (Chromosphere 18, Chrompack, Bergen op Zoom, The Netherlands) was used to separate individual compounds which were detected using a Kratos Superfl ow 773 detector (Separations, H. Y. Ambacht, The Netherlands). UV absorbance was detected at $280 \mathrm{~nm}$. The solvent phase was methanol and $1 \%$ acetic acid in water $(30: 70$, vol : vol ). The solvent flow was $0.5 \mathrm{~mL} / \mathrm{min}$, and the col umn temperature was $20^{\circ} \mathrm{C}$. 2,4DNT was determined with a C18 reverse-phase column using methanol (98\%) and $1 \%$ acetic acid in water (40: 60 , vol:vol) as solvent phase with a flow of $0.5 \mathrm{~mL} / \mathrm{min}$. UV absorbance was detected at $240 \mathrm{~nm}$. 2,4DAT was quantified with two $\mathrm{C} 18$ in series reverse-phase columns using methanol (98\%) and $0.5 \%$ acetic acid in water $(\mathrm{pH}$ $=4.5$ ) in a 40:60 ratio as solvent phase with a flow of 0.4 $\mathrm{mL} / \mathrm{min}$. UV absorbance was detected at $290 \mathrm{~nm}$. 5ASA was detected with two C18 in series reverse-phase columns using methanol (98\%) and $0.5 \%$ acetic acid in water $(\mathrm{pH}=4.5)$ in a 80:20 ratio as solvent phase with a flow of $0.3 \mathrm{~mL} / \mathrm{min}$. UV absorbance was detected at 300 $\mathrm{nm}$. NB and AN were determined with two C18 in series reverse-phase column using methanol (98\%) and 0.5\% acetic acid in water $(\mathrm{pH}=4.5)$ in a $50: 50$ ratio as solvent phase with a flow of $0.3 \mathrm{~mL} / \mathrm{min}$. UV absorbance was detected at $230 \mathrm{~nm}$. Aromatic amines were also determined col orimetrically after reacting with 4-dimethylaminobenzaldehyde- $\mathrm{HCl}$ (Ehrlich Reagent) according to the method described by Oren et al. (1991). The pH was determined immediately after sampling with a model 511 pH-meter (Knick, Berlin, Germany) and a model N61 double electrode (Scot Gerade, H ofheim, Germany). Methane and volatile fatty acids (VFA) were determined by gas chromatography as described elsewhere (Sierra and Lettinga, 1991). All the other analytical determinations were performed as described in Standard Methods for Examination of Water and Wastewater (APHA, 1985).

Laboratory Continuous UASB Reactor Experiments. The continuous reactor experiments were performed in four separate glass UASB reactors $(0.145 \mathrm{~m}$ in length and $0.039 \mathrm{~m}$ i.d.) with liquid volumes of 160 $\mathrm{mL}$ placed in a temperature-controlled room at $30 \pm 2$ ${ }^{\circ} \mathrm{C}$. Reactor 1 (R1), reactor 2 (R2), and reactor $3(\mathrm{R} 3)$ were inoculated with $20 \mathrm{~g}$ of volatile suspended solids (VSS) per liter of an sludge mixture: Shell Nederland Chemie anaerobic granular sludge and 2NP-adapted anaerobic granular sludge in a 2:1 ratio. Reactor 4 (R4) was started immediately after the experiment in R2 was finished by shifting the nitroaromatic compound (NB instead 4NBC) in the feeding. The reactors were started up (except R4) with partially neutralized $(\mathrm{pH}=6.0$, using a $10 \mathrm{~N} \mathrm{NaOH}$ solution) VFA mixture (acetate:propionate:butyrate, 23: 34:41, on a COD basis) at a concentration of $4 \mathrm{~g} \mathrm{COD/L}$ for 15 days (hydraulic retention times (HRTs) are $8 \mathrm{~h}$, unless otherwise indicated). Thereafter, the reactors received subtoxic concentrations of the nitroaromatic compounds in addition to the VFA substrate: R1, 60 $\mathrm{mg} / \mathrm{L}$ 5NSA; R2, $20 \mathrm{mg} / \mathrm{L}$ 4NBc; R3, $5 \mathrm{mg} / \mathrm{L}$ 2,4DNT. Subtoxic concentrations were defined as those causing a $50 \%$ inhibition of acetoclastic methanogens and were determined previously (Donlon et al., 1995). R4 received $50 \mathrm{mg} / \mathrm{L} \mathrm{NB}$ in addition to $1 \mathrm{~g} \mathrm{COD/L}$ of glucose as cosubstrate. The methane production was measured with $10 \mathrm{~L}$ M ariotte flasks filled with a $3 \%(\mathrm{w} / \mathrm{v}) \mathrm{NaOH}$ solution to scrub out the carbon dioxide from the biogas.

Determination of Nitroaromatic Reduction Rate. The nitroaromatic-reducing activity of the sludge sampled from R1 was also determined. The vials were set up similarly to the biodegradation technique outlined previously (Razo-Flores et al., 1996; Donlon et al., 1996). The test compound (5NSA) was introduced into the vials at concentrations of $100 \mathrm{mg} / \mathrm{L}$. Reduction of the nitroaromatic to its corresponding aromatic amine was monitored by measuring the loss in the nitro-group absorbance. Acetate and a VFA mixture (500 mg COD/L) were used to supply the electrons needed for the nitroaromatic reducing activity. Sludge that was autodaved $(1.1 \mathrm{~kg} /$ $\mathrm{cm}^{2}$ and $121^{\circ} \mathrm{C}$ ) for $1 \mathrm{~h}$ served as the control. All results are reported as the mean value of triplicate incubated experiments.

Biodegradation of Aromatic Amines. The biodegradation assay was conducted for the granular sludge sampled from all the columns as outlined previously (Razo-Flores et al., 1996) for more than 170 days. The aromatic amines 5ASA, 4ABC, and 2,4DAT were tested at concentrations of 300,300 , and $130 \mathrm{mg} / \mathrm{L}$, respectively, in the vials containing sludge samples withdrawn from $\mathrm{R} 1, \mathrm{R} 2$, or R3. AN was tested at $100 \mathrm{mg} / \mathrm{L}$ using sludge from R4. The aromatic amines were tested as the only carbon and energy source. The methane produced was monitored by periodic measurement of the headspace gas 
Table 1. Operational Parameters and Treatment Efficiency during Continuous Operation of the UASB Reactors (160 $\mathrm{mL}$ ) Treating 5-Nitrosalicylic Acid (5NSA), 4-Nitrobenzoic Acid (4NBc), 2,4-Dinitrotoluene (2,4DNT), and Nitrobenzene (NB) Together with Cosubstrates during the Final Period of Reactors Operation

\begin{tabular}{|c|c|c|c|c|}
\hline reactor & R1 (5NSA) & $\mathrm{R} 2(4 \mathrm{NBC})$ & R3 $(2,4 \mathrm{DNT})$ & R4 (NB) \\
\hline $\begin{array}{l}\text { final period reactor operation (d) } \\
\text { operational parameters }\end{array}$ & $200-253$ & $300-356$ & $162-202$ & $1-100$ \\
\hline cosubstrate influent (g COD/L) & $3.6^{a}$ & $3.6^{\mathrm{b}}$ & $4.0^{a}$ & $1.0^{\mathrm{b}}$ \\
\hline cosubstrate loading rate (g COD/L-d) & 13.3 & 9 & 12.8 & 0.9 \\
\hline nitroaromatic concentration influent (mg/L) & 150 & 125 & 120 & 50 \\
\hline nitroaromatic loading rate $(\mathrm{mg} / \mathrm{L}-\mathrm{d})$ & 553 & 312 & 384 & 43 \\
\hline hydraulic retention time $(\mathrm{h})$ & 6.5 & 9.6 & 7.5 & 28 \\
\hline efficiency & & & & \\
\hline cosubstrate removal (\%) & $99.5 \pm 0.5$ & $96.8 \pm 1.4$ & $98.5 \pm 1.8$ & $86.6 \pm 4.3$ \\
\hline $\begin{array}{l}\text { cosubstrate conversion to } \mathrm{CH}_{4}\left(\% \mathrm{COD}_{\text {in }}\right) \\
\text { nitroarmatic elimination }(\%)^{\mathrm{c}}\end{array}$ & $\begin{array}{l}94 \pm 21.5 \\
>99.2\end{array}$ & $\begin{array}{l}101.1 \pm 10 \\
>992\end{array}$ & $\begin{array}{l}97.6 \pm 15.2 \\
>99.9\end{array}$ & $\begin{array}{l}89.4 \pm 16.3 \\
>99.9\end{array}$ \\
\hline aromatic amine molar yield $(\%)^{c}$ & $2.8 \pm 2.8$ & $15.5 \pm 3.9$ & $52.4 \pm 5.6$ & $91.5 \pm 1.3$ \\
\hline
\end{tabular}

a Volatile fatty acids (VFA) mixture as a cosubstrate. ${ }^{b}$ Glucose as a cosubstrate. ${ }^{c}$ Determined by HPLC.

using gas chromatography. Methane production due to the mineralization of aromatic amines was calculated by subtracting background methane production in the sludge blank controls from that in the vials with test compound. The corrected methane production was expressed as a percentage of the theoretical methane production (TMP) expected from the mineralization of the aromatic amine according to the Buswell equation (Tarvin and Buswell, 1934). The specific mineralization rate of the aromatic amines was calculated by converting the measured milligrams of COD-CH${ }_{4}$ to milligrams of compound of the corresponding aromatic amine. The conversion factors are referred to in COD units $(\mathrm{g} / \mathrm{g})$ : $1.358,1.626,2.095$, and 2.405 for $5 A S A, 4 A B c, 2,4 D A T$, and $A N$, respectively. For methane, a factor of $2.577 \mathrm{~g}$ of $\mathrm{COD} / \mathrm{L}$ of $\mathrm{CH}_{4}$ at $30{ }^{\circ} \mathrm{C}$ was utilized. Parallel experiments where the sludge received the specific methanogenic inhibitor 2-bromoethanesulfonate (BESA, $50 \mathrm{mM}$ ) were also established to identify intermediates of 5ASA degradation. All results are reported as the mean value of triplicate incubated experiments.

Chemicals. Chemicals were purchased from either J annsen Chimica (Tilburg, The Netherlands), Merck (Darmstadt, Germany), or Sigma (Bornem, Belgium). All chemicals were of the highest purity available and were not purified further. The purity of all standards was $95 \%$ or greater.

\section{Results}

Anaerobic Treatment of Nitroaromatics in UASB Reactors. Four $160 \mathrm{~mL}$ UASB reactors were operated to investigate the fate of nitroaromatics under anaer obic treatment. All the reactors (except R4) were initially started up after a 15 day adaptation period to VFA. After this adaptation time period, the reactors were initially fed with subtoxic concentrations of the nitroaromatics. Either VFA or glucose was used as a cosubstrate to provide the electrons for the reduction of nitroaromatics. The concentration of nitroaromatic in the influent was increased periodically after at least 10 HRTs and when greater than $75 \%$ removal of nitroaromatic and cosubstrate was obtai ned. The rationale behind this approach is that the sludge is expected to withstand higher concentrations of the incoming nitroaromatic by reducing the nitro group to the less toxic amino group. The operational parameters and treatment efficiencies obtained during the continuous operation of the four UASB reactors treating 5NSA (R1), 4NBC (R2), 2,4DNT (R3), and NB (R4) in the final period of the reactor operation are summarized in Table 1.

5NSA was reduced at high efficiencies during the whole experimental period in R 1 (Figure 1 and Table 1).
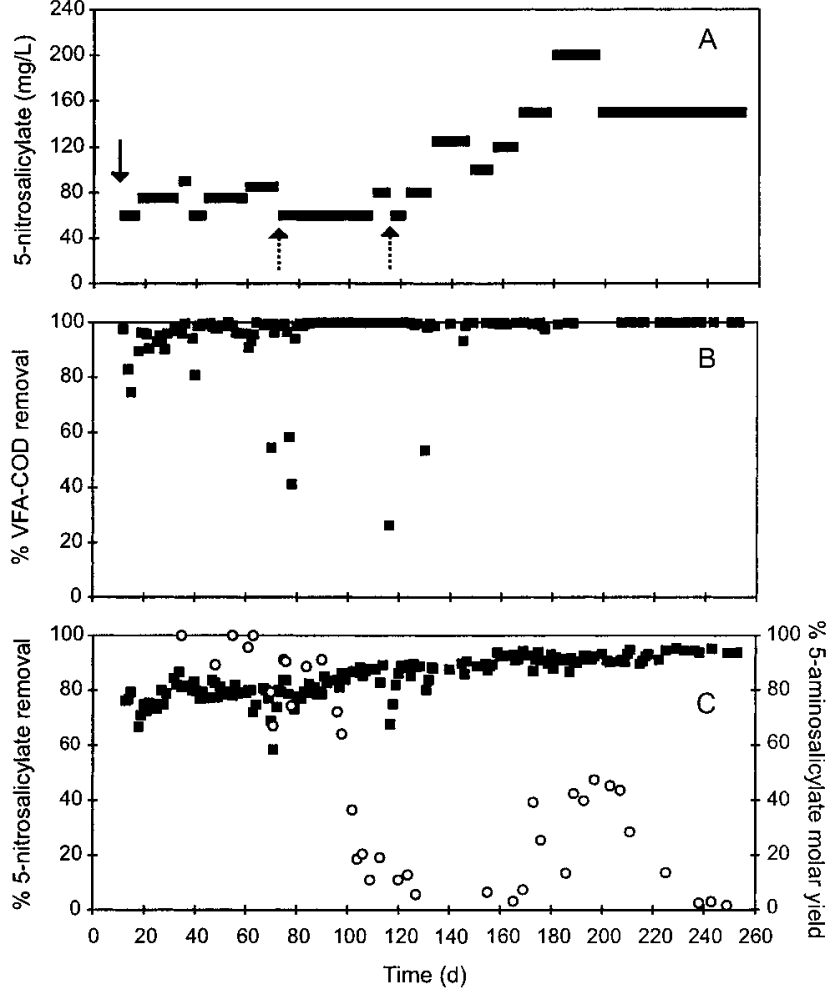

Figure 1. Operational efficiency during the continuous anaerobic treatment of 5-nitrosalicylate: (A) 5-nitrosalicylate concentration in the influent; (B) \%VFA-COD removal; (C) \% 5-nitrosalicylate removal as determined by loss in UV at $280 \mathrm{~nm}(\square)$, 5 -aminosalicylate recovery as a percentage (molar terms) of 5 -nitrosalicylate eliminated $(0)$. The solid arrow indicates the introduction of 5-nitrosalicylate in the influent. Up dotted arrows indicate $\mathrm{pH}$ drop.

5ASA was recovered in stoichiometric amounts during the first 90 days of operation. However, after day 100, less than $20 \%$ of the 5NSA removed was recovered as the corresponding aromatic amine (Figure 1C), indicating that 5ASA was transformed further. The system demonstrated to be sensitive to $\mathrm{pH}$ changes; on days 70 and 116, the pH dropped from 7.3 to 6.7 and 6.1, respectively, producing a sharp decrease in both the VFA removal and nitro reduction (upward dotted arrows in Figure 1A). Consequently, the 5NSA concentration in the influent was lowered to protect the biomass against toxic effects. After the VFA removal and the nitro reduction stabilized, the 5NSA concentration in the influent was again increased to a maximum of $150 \mathrm{mg} / \mathrm{L}$. A further increase of 5NSA in the influent to $200 \mathrm{mg} / \mathrm{L}$ produced a temporary accumulation of 5ASA in the effluent between days 


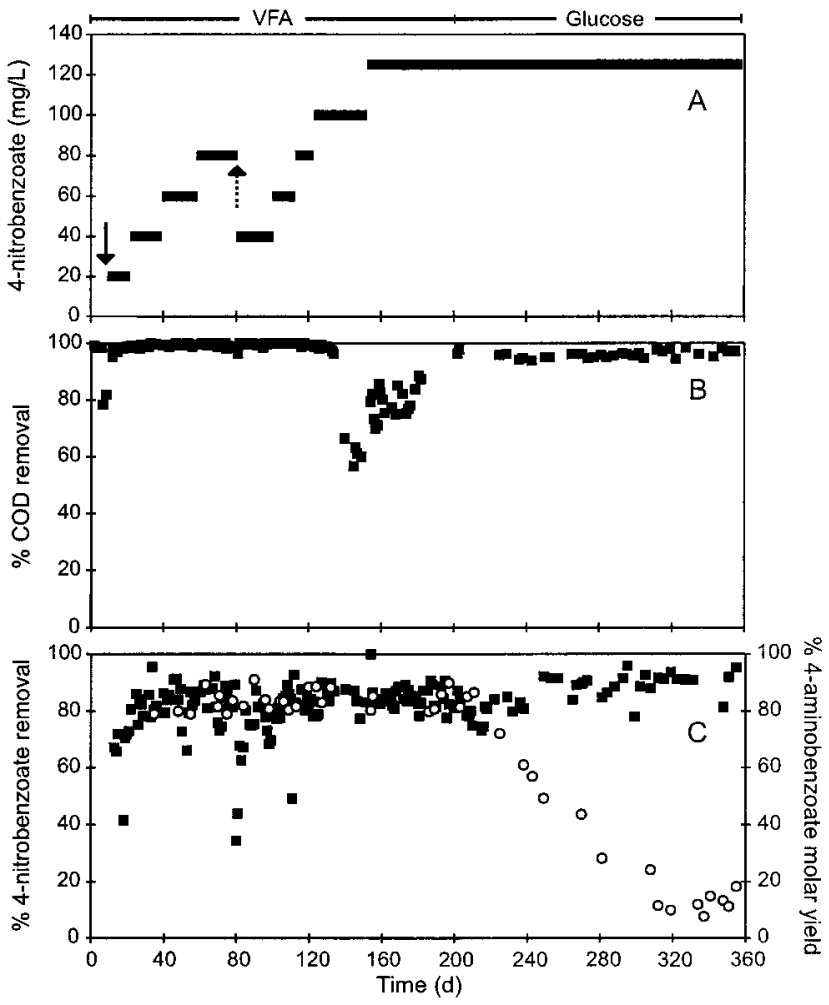

Figure 2. Operational efficiency during the continuous anaerobic treatment of 4-nitrobenzoate: (A) 4-nitrobenzoate concentration in the influent; (B) \%COD removal; (C) \% 4-nitrobenzoate

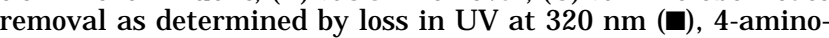
benzoate recovery as a percentage (molar terms) of 4-nitrobenzoate removed $(\bigcirc)$. For the other symbols, see legend of Figure 1.

170 and 220. The VFA removal was quite high over the course of the experimental period, and the methane production accounted for $94 \%$ of the VFA consumed during the final period of reactor operation.

The time course of the treatment performance of R2 treating 4NBC is shown in Figure 2. R2 was operated for a 356 day period. VFA mixture $(4 \mathrm{~g}$ COD/L ) was used as cosubstrate from day 0 to day 200, whereas glucose (4 g COD/L ) was used from day 201 and onward. During the VFA period, 4NBc was reduced at high efficiencies and $4 \mathrm{ABC}$ was recovered in stoichiometric amounts, indicating that the aromatic amine produced was not degraded. On day 80 , there was a pH drop (upward dotted arrow in Figure 2A) and 4NBc concentration in the influent was lowered to protect the biomass against toxic effects. Afterward the $4 \mathrm{NBC}$ concentration was again increased gradually up to $120 \mathrm{mg} / \mathrm{L}$. After the cosubstrate was shifted to glucose, the $4 \mathrm{NBC}$ reduction was still highly efficient. On day 225, the recovery of $4 A B C$ steadily started to decrease to less than $15 \%$ (molar yield) by the end of reactor operation (Table 1 ), indicating that a population of $4 \mathrm{ABC}$ degraders had developed. The COD removal (VFA or glucose) was greater than $95 \%$ during almost the entire period operation. In this reactor the measured methane production accounted for $101 \%$ of the glucose-COD consumed.

R3 treating 2,4DNT gave high nitro-group reduction efficiencies over the course of the experimental period even at 2,4DNT concentrations of $120 \mathrm{mg} / \mathrm{L}$. It was not possible to apply higher 2,4DNT concentrations due to its limited aqueous solubility. 2,4DAT was recovered in stoichiometric amounts until day 125 . Thereafter, the aromati c amine recovered accounted for only $52 \%$ molar yield of the 2,4DNT removed, indicating its further transformation. VFA removal efficiency was quite high over the course of the experiment (98.5\%). Methane production accounted for $97 \%$ of the VFA consumed in this reactor.

R4 treating NB was started in R2 immediately after the corresponding experiment was finished by shifting the nitroaromatic compound from $4 \mathrm{NBC}$ to NB. The concentration of both NB and glucose was kept constant for the entire period of reactor operation (100 days). The reduction of NB was highly efficient (>99.9\%) with the concomitant production of AN. There was 92\% AN recovery (molar yield) as determined by HPLC in this reactor, indicating no further conversion of the aromatic amine produced. Glucose-COD removal efficiency was greater than $87 \%$ and the methane production accounted for $89 \%$ of the glucose-COD removed.

Nitroaromatic Reduction of 5NSA. At the end of the reactor operation, sludge was withdrawn from R1 to study the extent of chemical and biological nitro-group reduction of 5NSA. An abiotic nitroaromatic reduction to aromatic amine was obtained using autoclaved granular sludge accounting for $3.06 \mathrm{mg}$ of $5 \mathrm{NSA} /(\mathrm{g}$ of VSS-d). When acetate was used as electron donor the nitroaromatic reduction rate was not enhanced and accounted for $3.2 \mathrm{mg}$ of $5 \mathrm{NSA} /(\mathrm{g}$ of VSS-d). However, the rate was almost four times higher when living sludge was used with a VFA mixture as cosubstrate accounting for 11.32 mg of $5 \mathrm{NSA} /(\mathrm{g}$ of VSS-d), indicating a biological enhance ment of the nitroaromatic reduction rate. The percentage of 5ASA recovered in this case, measured as molar yield, was $99.8 \%$.

Mineralization of Aromatic Amines by Sludge from the UASB Reactors. The aromatic amines produced from the reduction of the nitroaromatics from R1, $\mathrm{R} 2$, and R3 were used to study the mineralization potential of the sludges sampled from these continuous reactors. Table 2 indicates that 5ASA and $4 A B C$ were mineralized by all the three sludges as the methane production was higher than 65\% of the TMP. 2,4DAT and AN amended sludges produced low \%TMP after long incubation periods, indicating the recalcitrance of these compounds under methanogenic conditions. In the experiment conducted with R1 sludge and the specific methanogenic inhibitor, BESA, 5ASA was converted to mainly acetate, which equaled approximately $75 \%$ of the COD-5ASA added after correcting for the acetate levels in the sludge blank controls (results not shown). However, we did not detect any aromatic intermediate in uninhibited or BESA inhibited cultures.

\section{Discussion}

Anaerobic Treatment of Nitroaromatics in UASB Reactors. In a previous report, we have shown that nitroaromatic compounds are reduced to less toxic aromatic amine products (Donl on et al., 1995). This detoxification process allowed the treatment of mononitrophenols in laboratory-scale UASB reactors even at nitroaromatic loading rates of $910 \mathrm{mg} /(\mathrm{L}-\mathrm{d})$ and cosubstrate loading rates up to $13.3 \mathrm{~g}$ of $\mathrm{COD} /(\mathrm{L}-\mathrm{d})$, with greater than $87 \%$ cosubstrate-COD removal efficiency (Donlon et al., 1996). The results of the present study confirm that extensive detoxification can be obtained with 5NSA, $4 \mathrm{NBC}, 2,4 \mathrm{DNT}$, and NB as well. Initially, all the nitroaromatics were transformed stoichiometrically to their corresponding aromatic amines, and after long reactor operation, degradation of 5NSA and 4NBc to nonaromatic products was observed in R1 and R2. In the case of R3, 2,4 DNT was completely reduced, but only $52 \%$ of the 
Table 2. Anaerobic Batch Mineralization of Aromatic Amines to Methane by Sludge Sampled from the Reactors Treating 5-Nitrosalicylate (R1), 4-Nitrobenzoate (R2), and 2,4-Dinitrotoluene (R3)

\begin{tabular}{|c|c|c|c|c|c|c|c|c|c|}
\hline \multirow{2}{*}{$\begin{array}{c}\text { reactor } \\
\text { aromatic amine tested }\end{array}$} & \multicolumn{3}{|c|}{ R1 } & \multicolumn{3}{|c|}{$\mathrm{R} 2$} & \multicolumn{3}{|c|}{ R3 } \\
\hline & 5ASA & $4 A B C$ & 2,4DAT & 5ASA & $4 A B C$ & 2,4DAT & 5ASA & $4 A B C$ & 2,4DAT \\
\hline sampling day & 175 & 175 & 175 & 175 & 175 & 175 & 175 & 175 & 175 \\
\hline $\begin{array}{l}\text { concentration assayed } \\
(\mathrm{mg} / \mathrm{L})\end{array}$ & 300 & 300 & 130 & 300 & 300 & 130 & 300 & 300 & 130 \\
\hline methane $^{\mathrm{a}}(\% \mathrm{TMP})$ & $74.9 \pm 0.8$ & $65.2 \pm 17$ & $-0.7 \pm 1.6$ & $69.2 \pm 3$ & $82 \pm 2.9$ & $5.7 \pm 4$ & $71.8 \pm 0.3$ & $91 \pm 0.3$ & $4.9 \pm 5.1$ \\
\hline lag phase $(d)$ & $<5$ & 120 & $>170$ & 18 & 60 & $>170$ & 30 & 110 & $>170$ \\
\hline max mineralization & 13.2 & 2.98 & $\sim 0$ & 8 & 6.8 & $\sim 0$ & 15.9 & 4.73 & $\sim 0$ \\
\hline
\end{tabular}

rate (mg/g VSS-d)

a Methane production was corrected for the values in the sludge blank controls, which were used for comparison to the theoretical methane production (TMP of the test compound).

compound was recovered as 2,4DAT, suggesting partial transformation to an unidentified aromatic compound.

Continuous reactor studies for the treatment of 5NSA and $4 \mathrm{NBC}$ are not reported in the literature. 2,4DNT removal of more than $99.9 \%$ has been reported by Berchtold et al. (1995), using a fluidized-bed anaerobic granular activated carbon (GAC) reactor operated for almost 600 days with ethanol as cosubstrate. However, the contribution of adsorption onto the GAC in the overall removal of 2,4DNT is not described. The 2,4DNT loading rate applied in $\mathrm{R} 3$ of our study was double that applied in the GAC reactor ( $183.3 \mathrm{mg} / \mathrm{L}-\mathrm{d})$ of the cited study.

The effective treatment regimens applied for the treatment of highly toxic nitroaromatics rely mainly on three key factors, as shown in Figure 4: reductive anaerobic detoxification to products of lower toxicity as demonstrated in Donlon et al. (1995, 1996) and the present work; good hydraulic and gas mixing conditions minimizing biological dead space and preventing localized high concentrations of the toxic nitroaromatic compounds (Grobicki and Stuckey, 1991; van der Meer, 1979); and protection of the methanogens inside the granules (presence of less toxic aromatic amines due to the reducing conditions) from toxic compounds of the bulk of the reactor (nitroaromatic compounds).

Effects of Nitrogroup Position on the Nitroaromatic Reduction. The rate of nitro-group reduction of 5NSA indicated that results are enhanced when there is an electron donor available other than acetate as reported previously (Donlon et al., 1996). Autoclaved (dead) sludge was capable of reducing 5NSA, at rates 3-4-fold lower than those for living sludge, indicating that abiotic processes (mediated by cofactors or other sludge components) played an important role in the nitroreduction observed. Similar behavior has been observed previously in autoclaved sludge reducing nitrophenols (Donlon et al., 1996) and in the degradation of carbon tetrachloride (van Eekert et al., 1998).

When comparing the reduction rate of nitroaromatics using the VFA mixture (Donlon et al., 1996; this work), it was observed that the nitro-group reduction in the ortho position proceeded 2-4 times faster with respect to the meta and para positions, respectively. These results indicate that the position of the nitro group in relation to the other susbstituents in the aromatic ring plays a key role in the rate of nitro-group reduction. Preuss and Rieger (1995) indicated that the reduction rate of nitro compounds in general is determined by the chemical properties of the whole molecule and is therefore influenced by other ring substituents. Hudlicky (1984) reported a preferential reduction of nitro group in the ortho position with resonance electron-donating groups (e.g., $-\mathrm{NH}_{2}$ or $-\mathrm{OH}$ ) in the 1-position for both chemical and enzymatic reduction. McCormick et al. (1976) stated that the rate of reduction of nitro compounds by enzyme

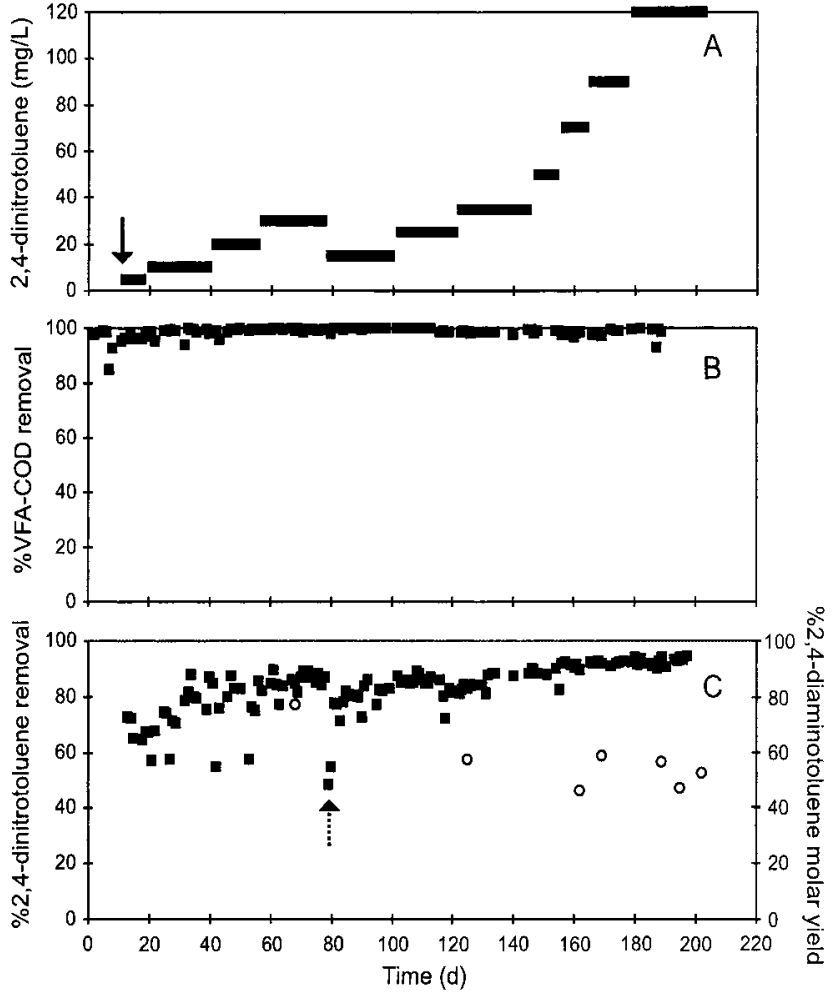

Figure 3. Operational efficiency during the continuous anaerobic treatment of 2,4-dinitrotoluene: (A) 2,4-dinitrotol uene concentration in the influent; (B) \%VFA-COD removal; (C) 2,4dinitrotoluene removal as determined by loss in UV at $260 \mathrm{~nm}$ (घ), 2,4-diaminotoluene recovery as a percentage (molar terms) of 2,4-dinitrotoluene removed (O). For the other symbols see legend of Figure 1.

preparations from Veillonel la alkal escens increases with increasing electron-withdrawing power of the groups at the para position in the following order: $-\mathrm{NH}_{2}<-\mathrm{OH}$ $<-\mathrm{H}<-\mathrm{CH}_{3}<-\mathrm{COOH}<-\mathrm{NO}_{2}$. The same authors stated that biologically mediated reduction mainly occurred at the ortho rather than at the para position in the case of nitroanilines and nitrophenols. On the other hand, the rates of nitroreduction increases as more nitro groups are placed on the aromatic ring (McCormick et al., 1976).

Mineralization of Aminoaromatics by Sludge from Reactors. The anaerobic sludges sampled from the reactors were incubated with the nontoxic concentrations of aromatic amines corresponding to the parent nitroaromatic compound in the reactor feed. It was observed that 5ASA and $4 A B C$ were completely mineralized to methane by all three sludges, while 2,4DAT was not mineralized at all. The long lag phase prior to $4 A B C$ mineralization was due to the time of sampling; the sludge was sampled from the reactor on day 175 when it was not yet fully 
1) Reductive detoxification

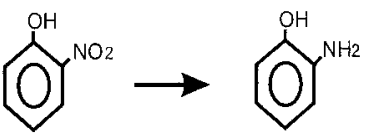

2) Hydraulic mixing

3) Protection inside biofilm
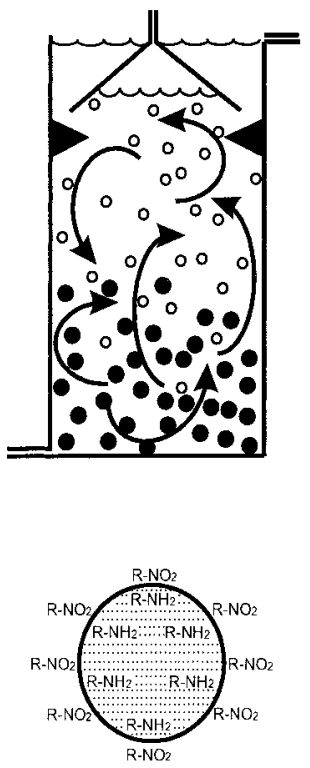

sludge granule

Figure 4. Three factors contributing to detoxification of nitroaromatics in upflow anaerobic sludge bed reactors.

adapted. $4 A B C$ degradation was first evident in R2 after day 225 . These results indicate the possibility that the microorganisms involved in the 5ASA and $4 A B C$ mineralization are the same. In the literature, $4 A B c$ is reported to be degraded in methanogenic consortia (Battersby and Wilson, 1989; Razo-Flores et al., 1996). The mineralization of 5ASA was reported previously using 2NP-adapted granular sludge after a lag phase of 65 days (Razo-Flores et al., 1996). 2,4DAT was not mineralized in batch assays, but the compound was removed in part, indicating that 2,4DAT was partially transformed to a nonidentified and nondegradable metabolite in R3. The 4ABc-adapted granular sludge from R4 was unable to carboxylate AN, confirming the recalcitrance of AN under methanogenic conditions (de Alexandra et al., 1993).

One of the reactions that has been demonstrated to take place during the mineralization of aromatic amines is deamination from the aromatic ring of 2-aminophenol by an anaerobic methanogenic consortium to produce phenol, which was mineralized afterward (Tseng and Yang, 1994). Bisaillon et al. (1993) described a methanogenic consortium that was able to carboxylate and dehydroxylate 2-aminophenol to produce 3-aminobenzoate, which accumulated in the culture medium and was not further metabolized.

Other N-substituted aromatics have been reported to be transformed to compounds that are susceptible to be mineralized. Stevens et al. (1991) reported that an fermentative enrichment culture degrading the herbicide Dinoseb (2-sec-butyl-4,6-dinitrophenol) was able to transform Dinoseb to acetate and $\mathrm{CO}_{2}$. The following nitroaromatics were also transformed by this enrichment culture to the same end products: 4,6-dinitro-o-cresol, 3,5dinitrobenzoate, 2,4-dinitrotoluene, and 2,6-di nitrotoluene (1991). In the same way, Funk et al. (1993) reported that under anaerobic conditions 2,4,6-trinitrotoluene was reduced to 2,4,6-triaminotoluene, and a deeper transformation resulted in the accumulation of methylphloro-
A) Complete mineralization:

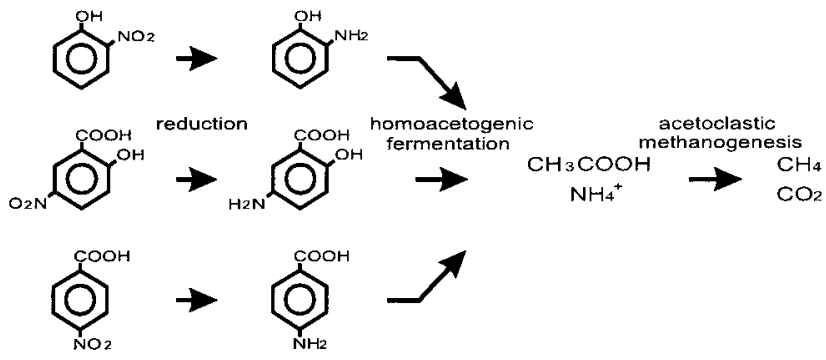

B) Biotransformation:
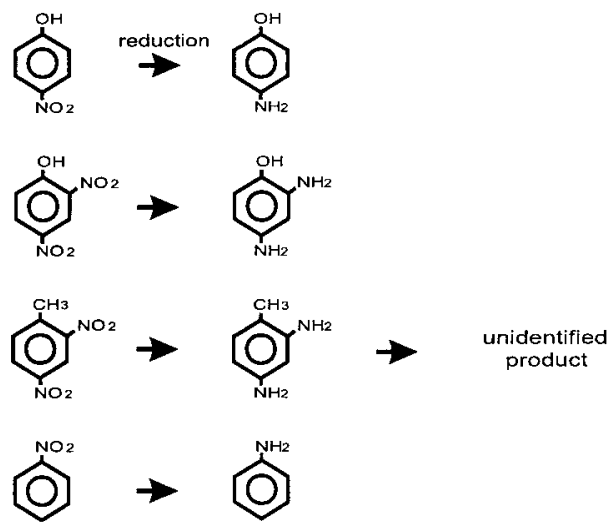

Figure 5. Final fate of selected nitroaromatics in the UASB reactors: (A) Complete mineralization of 2-nitrophenol, 5-nitrosalicylate, and 4-nitrobenzoate; (B) biotransformation of 4-nitrophenol, 2,4-dinitrophenol, 2,4-dinitrotoluene, and nitrobenzene (Donlon et al., 1996; this work).

glucinol and p-cresol via hydroxylation. Brown and Hamburger (1987) indicated that 4,4'-diamino-3,3'-dimethoxybiphenyl was eliminated in anaerobic sludge.

Reactions leading to the transformation of aromatic amines have been also reported under anoxic conditions. Schnell and Schink (1991) and de Alexandra (1994) have reported the mineralization of aniline under sulfatereducing and denitrifying conditions, respectively. The mineral ization proceeded via carboxylation of aniline in the para position to 4-aminobenzoate, which was activated to 4-aminobenzoyl-CoA and further metabolized by reductive deamination. This latter step has also been demonstrated with 2- and 3-aminobenzoate with strictly anaer obic bacteria (Lochmeyer et al., 1992). In the same way, acetylation of aromatic amines has been reported under nitrate-reducing conditions. Gilcrease and Murphy (1995) described the transformation of 2,4-diamino-6nitrotoluene to 4-acetylamino-2-amino-6-nitrotoluene, whereas Noguera and Freedman (1996) reported the transformation of 2,4-diaminotoluene to 2,4-diacetamidetoluene. The two acetylated compounds were not transformed further.

The results of this study and the previous ones (Donlon et al., 1996) indicate that UASB reactors can be applied to rapidly detoxify nitroaromatics and that certain nitroaromatics are even mineral ized to methane and carbon dioxide via homoacetogenic fermentation as described in Figure 5. However, several aromatic amines accumulated in the continuous reactors. These can be mineralized by a subsequent aerobic treatment step. Sequenced anaerobic-aerobic systems have been successfully applied for the treatment of aromatic compounds (Fiel d et al. 1995; Zitomer and Speece, 1993). NB and 2,4DNT were completely mineralized using this approach (Berchtold et al . 
1995; Dickel et al., 1993). Alternatively, anaerobic degradation can be obtained using el ectron acceptors aside from $\mathrm{CO}_{2}$.

\section{Acknowledgment}

This research was supported by the Consejo Nacional de Ciencia y Tecnología (CONACYT) from México. The authors thank Antonio Matamala for conducting some of the experimental work.

\section{References and Notes}

Alexandra de, M.; O'Connor, O. A.; Kosson, D. S. Metabolism of aniline under different anaerobic electron-accepting and nutritional conditions. Environ. Toxicol. Chem. 1993, 13, 233-239.

American Public Health Association. Standard methods for examination of water and wastewater, 16th ed.; American Public Health Association: Washington, DC, 1985.

Andreoni, V.; Baggi, G.; Bernasconi, S. Microbial degradation of nitrogenous xenobiotics of environmental concern. In Biotransformations: microbial degradation of health-risk compounds. Progress in industrial microbiol ogy; Singh, V. P., Ed.; Elsevier: Amsterdam, 1995; Vol. 32, pp 1-35.

Battersby, N. S.; Wilson, V. Survey of the anaerobic biodegradation potential of organic chemicals in digesting sludge. Appl. Environ. Microbiol. 1989, 55, 433-439.

Berchtold, S. R.; van der Loop, S. L.; Suidan, M. T.; Maloney, S. W. Treatment of 2,4-dinitrotoluene using a two-stage system: Fluidized-bed anaerobic granular activated carbon reactors and aerobic activated sludge reactors. Water E nviron. Res. 1995, 67, 1081-1091.

Bisaillon, J . G.; Lepine, F.; Beaudet, R.; Sylvestre, M. Potential for carboxylation-dehydroxylation of phenolic compounds by a methanogenic consortium. Can. J . Microbiol. 1993, 39, 642648.

Blum, D. J . W.; Speece, R. E. A database of chemical toxicity to environmental bacteria and its use in interspecies comparisons and correlations. Res. J. Water Pollut. Control. Fed. 1991, 63, 198-207.

Boyd, S. A.; Shelton, D. R.; Berry, D.; Tiedje, J . M. Anaerobic biodegradation of phenolic compounds in digested sludge. Appl. Environ. Microbiol. 1983, 46, 50-54.

Brown, D.; Hamburger, B. The degradation of dyestuffs: primary biodegradation under anaerobic conditions. Chemosphere 1987, 16, 1539-1553.

Dickel, O.; Haug, W.; Knackmuss, H. J. Biodegradation of nitrobenzene by a sequential anaerobic-aerobic process. Biodegradation 1993, 4, 187-194.

Donlon, B.; Razo-Flores, E.; Field, J .; Lettinga, G. Toxicity of $\mathrm{N}$-substituted aromatics to acetod astic methanogenic activity in granular sludge. Appl. Environ. Microbiol. 1995, 61, 38893893.

Donlon, B.; Razo-F lores, E.; Field, J .; Lettinga, G. Continuous detoxification, transformation and degradation of nitrophe nols in upflow anaerobic sludge blanket (UASB) reactors. Biotechnol. Bioeng. 1996, 51, 439-449.

van Eekert, M. H. A.; Schröder, T. J .; Stams, A. J . M.; Schraa, G.; Field, J . A. Degradation and fate of carbon tetrachloride in unadapted methanogenic granular sludge. Appl. Environ. Microbiol. 1998, 64, 2350-2356.

Field, J . A.; Stams, A. J . M.; Kato, M.; Schraa, G. Enhanced biodegradation of aromatic pollutants in coculture of anaerobic and aerobic bacterial consortia. Antonievan Leeuwenhoek 1995, 67, 47-77.

Fishbein, L. Aromatic amines. In The handbook of environmental chemistry; Hutzinger, O., E d.; Springer-Verlag: New York, 1984; Vol. 3, Part C; pp 1-40.

Funk, S. B.; Roberts, D. J .; Crawford, D. L.; Crawford, R. L. Initial-phase optimization for bioremediation of munition compound-contaminated soils. Appl. Environ. Microbiol. 1993, 59, 2171-2177.

Gilcrease, P. C.; Murphy, V. C. Bioconversion of 2,4-diamino6-nitrotoluene to a novel metabolite under anoxic and aerobic conditions. Appl. Environ. Microbiol. 1995, 61, 4209-4214.
Grobicki, A.; Stuckey, D. C. Hydrodynamic characteristics of the anaerobic baffled reactor. Water Res. 1992, 26, 371-378.

Hallas, L. E.; Alexander, M. Microbial transformation of nitroaromatic compounds in sewage effluent. Appl. Environ. Microbiol. 1983, 45, 1234-1241.

Hartter, D. R. The use and importance of nitroaromatic chemicals in the chemical industry. In Toxicity of nitroaromatic compounds; Rickert, D. E., Ed.; Chemical I ndustry I nstitute of Toxicology Series; Chemisphere: Washington, DC, 1985 pp 1-14.

Hirzel, S. 2-nitrophenol, 4-nitrophenol, BUA Report 75. Wissenschaftliche Verlagsgesellschaft: Stuttgart, Germany, 1993.

Hudlicky, M. Reductions in organic chemistry; Halsted Press: New York, 1984; p 74.

Knackmuss, H.-J. Potentials and limitations of microbes to degrade xenobiotics. In DECHEMA preprints soil decontami nation using biological processes; Karlsruhe, Germany, 1992; pp 3-9.

Knackmuss, H.-J . Basic knowledge and perspectives of bioelimination of xenobiotic compounds. J . Biotechnol. 1996, 51, 287-295

Kriek, E. Aromatic amines and related compounds as carcinogenic hazards to man. In Environmental carcinogenesis; Emmel ot, P., Kriek, E., Eds.; Elsevier: Amsterdam, 1979; pp 143-164.

Lochmeyer, C.; Koch, J .; Fuchs, G. Anaerobic degradation of 2-aminobenzoic acid (anthranilic acid) via benzoyl-coenzyme A (CoA) and cyclohex-1-enecarboxyl-CoA in a denitrifying bacterium. J . Bacteriol. 1992, 174, 3621-3628.

McCormick, N. G.; Feeherry, F. E.; Levinson, H. S. Microbial transformation of 2,4,6-trinitrotoluene and other nitroaromatic compounds. Appl. Environ. Microbiol. 1976, 31, 949958.

Meer van der, R. R. Anaerobic treatment of wastewater containing fatty acids in upflow reactors. Ph.D. Thesis, Delft University of Technology, 1979.

Noguera, D. R.; Freedman, D. L. Reduction and acetylation of 2,4-dinitrotoluene by a Pseudomonas aeruginosa strain. Appl . Environ. Microbiol. 1996, 62, 2257-2263.

Oren, A.; Gurevich, P.; Henis, Y. Reduction of nitrosubstituted aromatic compounds by the hal ophilic anaerobic eubacteria Haloanaerobium praevalens and Sporohalobacter marismortui. Appl. Environ. Microbiol. 1991, 57, 3367-3370.

Preuss, A.; Rieger, P.-G. Anaerobic transformation of 2,4,6trinitrotoluene and other nitroaromatic compounds. In Biodegradation of nitroaromatic compounds; Spain, J. C., Ed.; Plenum Press: New York, 1995; pp 69-85.

Razo-Flores, E.; Donlon, B.; Field, J .; Lettinga, G. Biodegradability of $\mathrm{N}$-substituted aromatics and alkylphenols under methanogenic conditions using granular sludge. Water Sci. Technol. 1996, 33 (3), 47-57.

Rieger, P.-G.; K nackmuss, H.-J . Basic knowledge and perspectives on biodegradation of 2,4,6-trinitrotoluene and related nitroaromatic compounds. In Biodegradation of nitroaromatic compounds; Spain, J., Ed.; Plenum: New York, 1995; pp $1-18$.

Schink, B. Fermentative degradation of nitrogenous aliphatic and aromatic compounds. In 5th International Symposium on Anaerobic Digestion; Hall, E. R., Hobson, P. N., Eds.; Pergamon Press: Oxford, U.K., 1988; pp 459-464.

Schnell, S.; Schink, B. Anaerobic aniline degradation via reductive deamination of 4-aminobenzoyl-CoA in Desulfobacterium anilini. Arch. Microbiol. 1991, 155, 183-190.

Sierra, R.; Lettinga, G. The effect of aromatic structure on the inhibition of acetoclastic methanogens in granular sludge. Appl. Microbiol. Biotechnol. 1991, 34, 544-550.

Spain, J. Synthetic chemicals with potential for natural attenuation. Biorem. J. 1997, 1, 1-9.

Stevens, T. O.; Crawford, R. L.; Crawford, D. L. Selection and isolation of bacteria capable of degrading dinoseb (2-sec-butyl4,6-dinitrophenol). Biodegradation 1991, 2, 1-13.

Swoboda-Colberg, N. G. Chemical contamination of the environment: sources, types, and fate of synthetic organic chemicals In Microbial transformation and degradation of toxic organic chemicals; Young, L. Y., Cerniglia, C. E., Eds.; Wiley-Liss: New York, 1995; pp 27-74. 
Tarvin, D.; Buswell, A. M. The methane fermentation of organic acids and carbohydrates. J . Am. Chem. Soc. 1934, 56, 17511755.

Tseng, S. K.; Yang, C. J . The reaction characteristics of waste water containing nitrophenol, treated using an anaerobic biological fluidized bed. Water Sci. Technol. 1994, 30, 233240.

Uberoi, V.; Bhattacharya, S. K. Toxicity and degradability of nitrophenols in anaerobic systems. Water Environ. Res. 1997, 69, 146-156.
U.S. EPA. Health and environmental effects profile of nitrotoluenes ( $0, \mathrm{~m}$ and $\mathrm{p}$ ). Report EPA/600/x-86/143; Environmental Criteria and Assessment Office: Cincinnati, $\mathrm{OH}$, 1986.

Zitomer, D. H.; Speece, R. E. Sequential environments for enhanced biotransformation of aqueous contaminants. Environ. Sci. Technol. 1993, 27, 227-244.

Accepted March 19, 1999.

BP9900413 